\title{
Uzaktan Manyetik Algılamada Manyetik Sensörlerin Hassasiyet Analizi
}

\author{
Precision Analysis Of Magnetic Sensors In Remote Magnetic Sensing
}

\author{
Hakan ÇITAK ${ }^{1}$ (D) \\ ${ }^{1}$ Balikesir Üniversitesi, Balıkesir Meslek Yüksekokulu, Elektrik ve Enerji Bölümü, 10145, Balıkesir, Türkiye
}

$\ddot{\mathbf{O z}}$

Son zamanlarda yapılan uzaktan algılama çalışmaları, düşük güç tüketimi, düşük fìyat, çevresel değişimlerden etkilenmeme, yüksek hassasiyet, yüksek güvenilirlik ve sağlamlık üzerinedir. Uzaktan manyetik algılama için kullanılan manyetik sensörler arasında; bobin, GMR, AMR, Fluxgate, Hall ve Squid sensörler yer almaktadır. Sensörün hassasiyeti ile fiyatı arasında ters orantı mevcuttur. Bu yüzden algılama mesafesine göre manyetik sensör ile maliyeti arasında optimum bir orantı kurmak gerekmektedir. Bu çalışmada 1200 sarımlı demir çekirdekli bir bobinin 1 A'lik AC akımda oluşturduğu manyetik alanın, GMR etki gösteren $\left.\mathrm{AC} 20\left(\mathrm{Co}_{0.94} \mathrm{Fe}_{0.06}\right)_{72.5} \mathrm{Mo}_{12.5} \mathrm{~B}_{15}\right)$ amorf tel ve bobin sensörle algılanabilme mesafesi ile birlikte çözünürlüğü arasındaki farkların belirlenmesi hedeflenmiştir. Bu doğrultuda sensörlerin konum kontrollü hareketi için 2D tarayıcı sistem tasarlanıp imal edilmiş ve sensörlerin aynı manyetik alan içindeki performansları makale kapsamında ayrıntılı olarak tartışılmıştır.

Anahtar Kelimeler: AC 20 Amorf Tel, Bobin, Manyetik Alan, Uzaktan Algilama

\begin{abstract}
The latest remote sensing studies are on low power consumption, low price, resistance to environmental alterations, high precision, high reliability and durability. Coil, GMR, AMR, Fluxgate, Hall and Squid are among the magnetic sensors that are used for remote magnetic sensing. There is an inverse proportion between precision of a sensor and its price. That's why an optimum proportion is needed between a magnetic sensor and its price depending on sensing distance. In this study, it is aimed to determine the differences between resolution and sensing distance of a magnetic field created by a 1200-turn coil with iron core, using AC20 (Co0.94Fe0.06)72.5Mo12.5B15) amorphous wire and a coil sensor that indicate GMR effect.

Despite the fact that magnetic flux density does not take value zero until x value takes infinite value in theory, it is not possible to read a voltage rating in every distance with a coil sensor in practice. The inducted voltage which decreases as distance increases could be read up to a certain distance through changing amplifier circuit gain. It appears to be a restrictive effect on this issue that amplifier block does not amplify after a certain number of amplifiers. Besides, as getting distant from the magnetic field source, the noise in the ambiance prevails and this noise amount amplifies via amplifier circuit thus damaging signal from, which appears to be among challenges in reading in sensor signals in practice.

The induction voltage that occurs in the search coil due to magnetic flux change has been brought within values that could be read through conducting in a sensitive op-amp circuit formed by TL081. Voltage rate has been gradually increased in order to amplify the sensor voltage rating as the distance between magnetic field source and the search coil. The voltages induced in areas, where magnetic flux lines are not proper and the directions vary on search coils that carry out sectional reading, are in the form of noise and are mostly lost in filter circuits. This kind of voltage signals should be separated into their harmonics through Fourier analysis and the harmonics that exhibit high variation should be observed.

In our study an amorphous wire is fed on voltage by an AC supply. Here the voltage restricts the current passing through the amorphous wire. Supply voltage and frequency are determined by physical features of the amorphous wire. The test carried out Show that when the amorphous wire is supplied by a $5 \mathrm{MHz}$ frequency, a great majority of magnetic moments tend to the same direction with the magnetic field applied, thus resulting in maximum impedance change. It is shown that changing supply voltage on the wire does not necessarily lead to
\end{abstract}


any structural change and that the voltage rating on the amorphous wire amplifies in proportion to supply voltage.

Accordingly, a 2D scanner system has been designed and manufactured for position control motion of the sensors, moreover performances of the sensors within the same magnetic field is discussed in detail within the scope of this article.

Keywords: AC 20 Amorphous Wire, Bobbin, Magnetic Field, Remote Sensin

\section{GİRIŞ̧}

Günümüzde uzaktan algılama; hava ve kara trafiğinin kontrolünde $[1,2]$, motorlardaki kalkınma akımının ölçülmesinde, endüstriyel otomasyon sistemlerinde pozisyon ve açı ölçümlerinde, disk ve teyp sistemleri için okuyucu kafalarda [3], yön belirlemede [4], tıpta beyin ve vücut fonksiyonlarını izleme [4,5] gibi farklı yöntemler ile farklı amaçlar için kullanılmaktadır. Tüm algılama yöntemlerinde önemli olan sensörde düşük güç tüketimi, düşük fiyat, çevresel değişimlerden etkilenmeme, yüksek hassasiyet, yüksek güvenilirlik ve sağlamlık olmaktadır. Sensörün hassasiyeti ile fiyatı arasında ters orantı mevcuttur. Bu yüzden algılama mesafesine göre sensör ile maliyeti arasında optimum bir orantı kurmak gerekmektedir. Düşük fiyat, düşük güç tüketimi ve sağlamlık değişkenleri dikkate alındığında manyetik algılamada bobin sensörler ve GMR etki gösteren amorf teller ön plana çıkmaktadır.

Bobin sensörler, Faraday’ın elektromanyetik indüksiyon kanununa göre çalışırlar ve manyetik akı değişiminin doğurduğu indüksiyon gerilimini çıktı olarak vermektedirler. $\mathrm{Bu}$ gerilim,

$$
\mathrm{V}=-\mu_{0} \cdot \mathrm{N} \cdot \mathrm{A} \cdot \frac{\mathrm{dH}}{\mathrm{dt}}
$$

şeklinde yazılabiliriz. Eğer bobin sensör, ferromanyetik bir nüve üzerine sarılırsa, bu durumda sensörde indüklenecek gerilim değeri,

$$
\mathrm{V}=-\mu_{0} \cdot \mathrm{N} \cdot \mathrm{A} \cdot \frac{\mathrm{d}(\mathrm{H}+\mathrm{M})}{\mathrm{dt}}
$$

bağıntısıyla bulunabilir.

Bobinin duyarlılığı; nüvenin manyetik geçirgenliğine, bobinin kesit alanına, sarım sayısına ve bobinden geçen manyetik akının değişim oranına bağlıdır.
Amorf tel ise genelde $\mathrm{Fe}, \mathrm{Co}, \mathrm{Ni}, \mathrm{Si}, \mathrm{B}$ karışımı bir alaşımdır. Si telin kırılması engellemek için kullanılmaktadır[6]. Amorf tellerin düşük anizotropi ve büyük manyetik gerinmeye sahip olması manyetik alanda telin direncinin aşırı büyümesine sebep olmaktadır. Aslında manyetik gerinme materyalin domain yapısına bağlı olarak değişmektedir.

Tablo 1'de manyetoelastik etkiyi kullanarak yapılacak manyetik algilamada tercih edilecek amorf materyallerin mekanik ve manyetik karakteristikleri verilmiştir [7].

Tablo 1. Bazı amorf tellerin teknik özellikleri

\begin{tabular}{lllllll}
\hline \multirow{2}{*}{ Amorf Alaşımlar } & $\begin{array}{l}\lambda_{\mathrm{s}} \\
\mathrm{x} 10^{-6}\end{array}$ & $\begin{array}{l}\mathrm{H}_{\mathrm{c}} \\
\mathrm{A} / \mathrm{cm}\end{array}$ & $\begin{array}{l}\mathrm{J}_{\mathrm{s}} \\
\mathrm{T}\end{array}$ & $\mathrm{HV}$ & $\begin{array}{l}\mathrm{R}_{\mathrm{p}} \\
\mathrm{N} / \mathrm{mm}^{2}\end{array}$ & $\begin{array}{l}\mathrm{E} \\
\mathrm{kN} / \mathrm{mm}^{2}\end{array}$ \\
\hline & & & & & & \\
$\mathrm{Fe}_{80} \mathrm{~B}_{14} \mathrm{Si}_{6}$ & +30 & 0,04 & 1,5 & 950 & & \\
$\mathrm{Fe}_{40} \mathrm{Ni}_{38}(\mathrm{Mo}, \mathrm{Si}, \mathrm{B})_{22}$ & +8 & 0,03 & 0,8 & 800 & $1500 \ldots$ & \\
$(\mathrm{Co}, \mathrm{Fe}, \mathrm{Mo})_{73}(\mathrm{~B}, \mathrm{Si})_{27}$ & $\sim 0,2$ & 0,003 & 0,55 & 1000 & & 150 \\
$\mathrm{Co}_{75} \mathrm{Si}_{15} \mathrm{~B}_{10}$ & $-3,5$ & 0,025 & 0,7 & 1000 & 2000 & \\
$\mathrm{Co}_{68} \mathrm{Ni}_{10} \mathrm{~B}_{14} \mathrm{Si}_{8}$ & -8 & & 0,85 & & &
\end{tabular}

Manyetik algılamada tercih edilen manyetik özellikler,

* Kolay mıknatıslanabilme; malzemedeki mıknatıs akısı yoğunluğunu sıfıra düşürebilmek için gerekli mıknatıs alanının (Hc) düşük olması

* Yüksek doyma akısı yoğunluğu (Js)

* Manyetik alan etkisiyle miknatıslanma yönünde boyda yeterli ve belirli bir uzama $(\lambda s)$;

$\frac{d \lambda}{d H}$ ve $\frac{d \lambda}{d B}$

*Yüksek sertlik (HV)

*Yüksek gerilme katsayısı (Rp)

Ayrıca düşük anizotropiye sahip amorf tellerin manyetik alan altında yüksek direnç göstermesi, tel içindeki elektronların manyetik alandan kazandıkları enerjiye de bağlanabilir. Bu enerji,

$$
\Delta \mathrm{E}=\mathrm{g} \mu_{\mathrm{j}} \mu_{\mathrm{B}} \mathrm{B}_{\mathrm{y}}
$$

ile bulunabilir. Burada g lande çarpanı, $\mu_{j}$ toplam manyetik moment ve $\mu_{\mathrm{B}}$ Bohr manyetonudur. Alandan aktarılan bu enerji elektronların kinetik enerjierini arttırarak, sinyal jeneratörünün sağladığı elektrik alandaki düzenli hareket bozulmaktadır. Bu da direncin aşırı büyümesine sebep olmaktadır. Bu konuda yapılan çoğu çalışmada amorf telin iki ucuna $5 \mathrm{MHz}$ frekansında $10 \mathrm{~V}$ genlikli AC sinyal uygulanmaktadır. Ayrıca devreden geçen akımı sınırlamak için de seri 10 $\mathrm{k} \Omega$ 'luk direnç kullanılmaktadır[8]. 


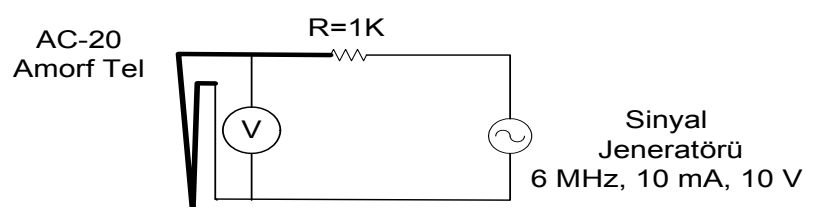

(a)

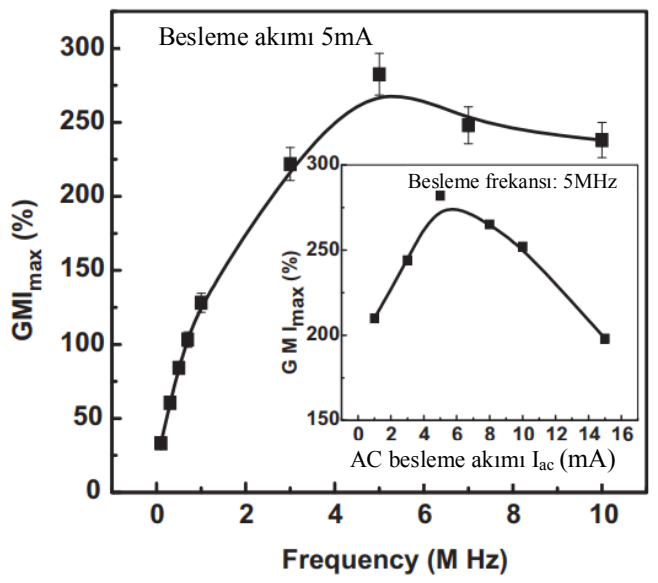

(b)

Şekil 1. Amorf telin manyetik sensör olarak kullanımı[8,9]

$\mathrm{Bu}$ çalışmada GMR etki gösteren AC20 $\left(\mathrm{Co}_{0.94} \mathrm{Fe}_{0.06}\right)_{72}$. ${ }_{5} \mathrm{Mo}_{12.5} \mathrm{~B}_{15}$ ) amorf tel ve 500 sarıml $4,2 \mathrm{mH}$ özindüksiyon katsayılı bir bobin sensör olarak kullanılmıştır. Bu sensörlerin manyetik alanı belirlenebilme mesafesi ve çözünürlüğü arasındaki farklar araştırılmıştır. Sensörlerin güç tüketimi, maliyeti ve manyetik alandaki performansları dikkate alınarak bir değerlendirme yapılmıştır.

\section{MATERYAL VE YÖNTEM}

\subsection{Manyetik Alan Kaynağı}

$\mathrm{Bu}$ çalışmada ilk olarak sensörlerin performans testi için manyetik alan kaynağı oluşturulmuştur. Bu doğrultuda sinyal jeneratörü, güç yükselteci, izolasyon transformatörü ve demir çekirdekli bir bobin Şekil 2'deki gibi ilişkilendirilmiştir.
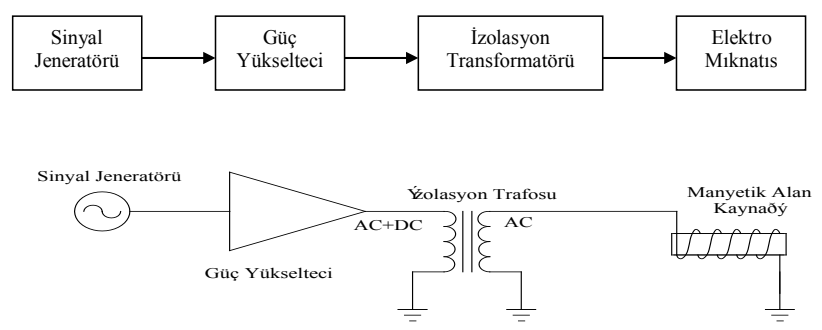

Şekil 2. Manyetik alan kaynağının blok diyagramı ve açık şeması
Sinyal jeneratörü ile üretilen $50 \mathrm{~Hz} 3 \mathrm{~V}$ genlikli $\mathrm{AC}$ sinyal amplifikatör aracılığıyla yükseltilmektedir. Amlifikatör çıkışı hem AC hem DC karakterde sinyal barındırdığ 1 için izolasyon transformatöründen geçirilerek sekonder sargıda saf AC sinyal sağlanmıştır. Bu genliği yükseltilmiş ve saf $A C$ hale getirilmiş sinyal 1200 sarımlı ve $35 \mathrm{mH}$ özindüksiyona sahip demir çekirdekli bir bobine verilmiştir(Şekil 3).

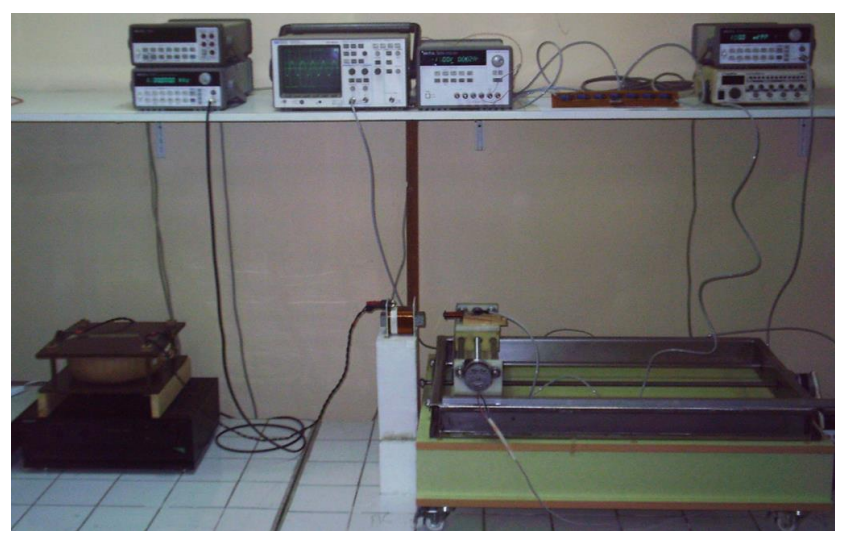

Şekil 3. Manyetik alan kaynağ1

\subsection{Bobin Sensör İle Uzaktan Algılama}

Bu çalışmada kesiti $0.28 \mathrm{~mm}^{2}, 500$ sarımlı, $4.2 \mathrm{mH}$ özindüksiyona sahip bir bobin, sensör olarak kullanılmıştır. Manyetik akı değişimi sebebiyle sensörde oluşan indüksiyon gerilimi, TL081 ile kurulmuş hassas opamp devresinden geçirilerek okunabilecek gerilim değerlerine getirilmiştir. Manyetik alan kaynağı ile bobin sensör arasındaki mesafe artıkça sensör gerilim değerini büyütmek için yükseltme oranı kademeli olarak arttırılmıştır.

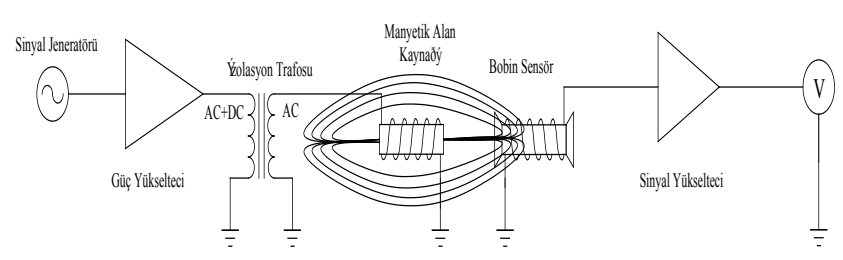

Şekil 4. Bobin sensör ile uzaktan algılama

Deneysel aşamada bobin sensör Şekil 3'te görülen 2D tarayıcı sistem üzerine yerleştirilmiş ve manyetik alan kaynağının karşısında her iki yönde de $1 \mathrm{~cm}$ aralıklarla iki boyutta hareket ettirilmiştir. Elde edilen sensör çıkış gerilimleri kaydedilerek grafiğe dönüştürülmüştür (Şekil 5). 


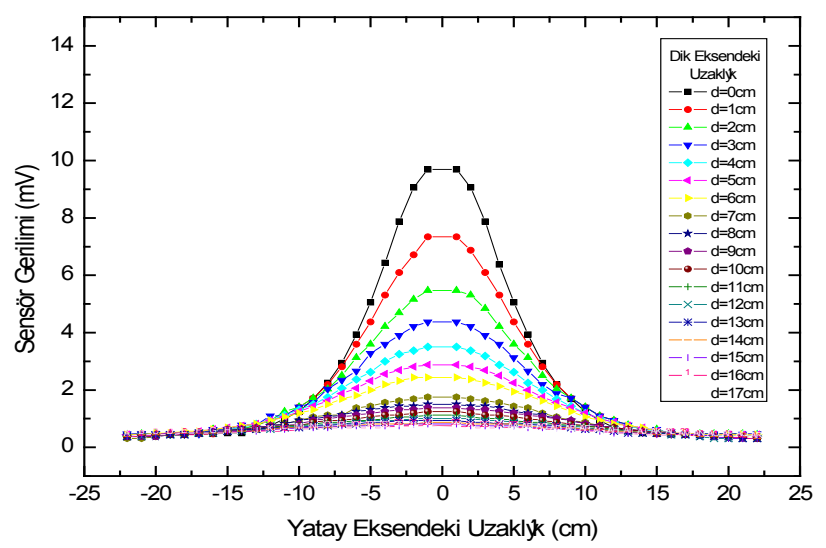

Şekil 5. Bobin sensör ile elde edilen gerilim değerlerinin değişimi

Şekil 5'teki değişimi açılayabilmek için $\mathrm{R}$ yarıçaplı içinden $\mathrm{i}$ akımı geçen bir halkanın kendisinden $\mathrm{x}$ kadar uzaklıkta oluşturduğu B manyetik akı yoğunluğu denklemini elde etmek gerekmektedir. Şekil 6 da görüldüğü gibi tarama düzleminde manyetik akı yoğunluğunun iki bileşeni mevcuttur. Dikkat edilirse dik bileşenler P noktasında birbirlerini götürmektedir.

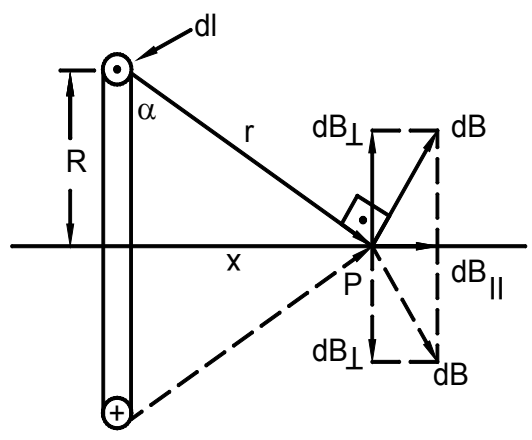

Şekil 6. Bir halkanın kendisinden x kadar uzaktaki manyetik akı yoğunluğu

P noktasındaki toplam manyetik akı yoğunluğu sadece $\mathrm{dB}_{\mathrm{n}}$ oluşmaktadır. O halde;

$$
\mathrm{B}=\int \mathrm{dB}_{\mathrm{II}}
$$

ile verilir.

Biot-Savart Kanununa göre;

$\mathrm{IB}_{\mathrm{II}}=\frac{\mu_{0} \cdot \mathrm{i} \cdot \mathrm{dl}}{4 \pi \cdot \mathrm{r}^{2}} \cdot \operatorname{Cos} \alpha$

şeklinde bulunur. Burada,

$$
\operatorname{Cos} \alpha=\frac{R}{r}=\frac{R}{\sqrt{R^{2}+x^{2}}}
$$

alınırsa,

$$
\mathrm{dB}_{\mathrm{II}}=\frac{\mu_{0} \cdot \mathrm{i} \cdot \mathrm{R}}{4 \pi \cdot\left(\mathrm{R}^{2}+\mathrm{x}^{2}\right)^{3 / 2}} \mathrm{dl}
$$

elde edilir. Bu durumda P noktasındaki manyetik akı yoğunluğu,

$$
\mathrm{B}=\int \mathrm{dB}_{\mathrm{II}}=\frac{\mu_{0} \cdot \mathrm{i} \cdot \mathrm{R}}{4 \pi \cdot\left(\mathrm{R}^{2}+\mathrm{x}^{2}\right)^{3 / 2}} \int \mathrm{dl}
$$

olur ve $\int \mathbb{d}$ integrali dairenin çevresini vereceği göz önünde tutulursa;

$$
B=\frac{\mu_{0} \cdot i \cdot R^{2}}{2\left(R^{2}+x^{2}\right)^{3 / 2}}
$$

denklemi elde edilir.

Şayet $\mathrm{x}>>\mathrm{R}$ ise devreye yakın noktalar göz önüne alınmaz, dolayısıyla eşitlik;

$$
\begin{aligned}
& \mathrm{B}=\int \mathrm{dB}_{\mathrm{II}}=\frac{\mu_{0} \cdot \mathrm{i} \cdot \mathrm{R}}{4 \pi \cdot\left(\mathrm{R}^{2}+\mathrm{x}^{2}\right)^{3 / 2}} \int \mathrm{dl} \\
& \mathrm{B}=\int \mathrm{d} \mathrm{B}_{\mathrm{II}}=\frac{\mu_{0} \cdot \mathrm{i}}{4 \pi \cdot \mathrm{x}^{3}} \int \mathrm{dl} \\
& \mathrm{B}=\frac{\mu_{0} \cdot \mathrm{i}}{4 \pi \cdot \mathrm{x}^{3}}(2 \pi \cdot \mathrm{R}) \\
& \mathrm{B}=\frac{\mu_{0} \cdot \mathrm{i} \cdot \mathrm{R}}{2 \mathrm{x}^{3}}
\end{aligned}
$$

dönüșür.

Telin çevrelediği alanın p. $\mathrm{R}^{2}$ olduğunu ve $\mathrm{N}$ tane sarımdan oluştuğunu düşünürsek manyetik akı yoğunluğu ifadesi;

$$
\mathrm{B}=\frac{\mu_{0} \cdot(\mathrm{N} \cdot \mathrm{i} \cdot \mathrm{A})}{2 \pi \cdot \mathrm{x}^{3}}
$$

şeklinde yazılabilir. Bu çalışmada manyetik alan kaynağ 1 olarak kullanılan bobin demir çekirdekli olduğundan manyetik akı yoğunluğu hesabı için,

$\mathrm{B}=\frac{\mu \cdot(\mathrm{N} \cdot \mathrm{i} \cdot \mathrm{A})}{2 \pi \cdot \mathrm{x}^{3}}$

bağıntısı kullanılabilir. 
Görüldüğü gibi Denklem 9 manyetik akı yoğunluğunun x uzaklığının küpüyle ters orantılı olarak değişmektedir. Bu durumu Şekil 5 ve Şekil 7 'teki değişimin grafiklerini de doğrulamaktadır.

Teorik olarak $\mathrm{x}$ değeri sonsuz değer alana kadar manyetik akı yoğunluğu sıfır değerini almamasına rağmen, pratikte bobin sensörle her uzaklıkta bir gerilim değeri okumak mümkün değildir. Uzaklık arttıkça azalan indüklenen gerilim, yükseltme devresinin kazancının değiştirilmesiyle belirli bir mesafeye kadar okunabilir. Belirli bir sayıda yükselteçten sonra yükselteç bloğunun yükseltme yapamaması bu konuda sınırlayıcı bir etken olarak karşımıza çıkmaktadır. Bununla birlikte manyetik alan kaynağından uzaklaştıkça ortamdaki gürültü miktarının daha baskın hale gelmesi ve yükseltme devresiyle bu gürültü miktarının da büyütülmesi ile sinyalin formunun bozulması sensör sinyalini okumadaki zorluklar olarak uygulamada karşımıza çıkmaktadır.

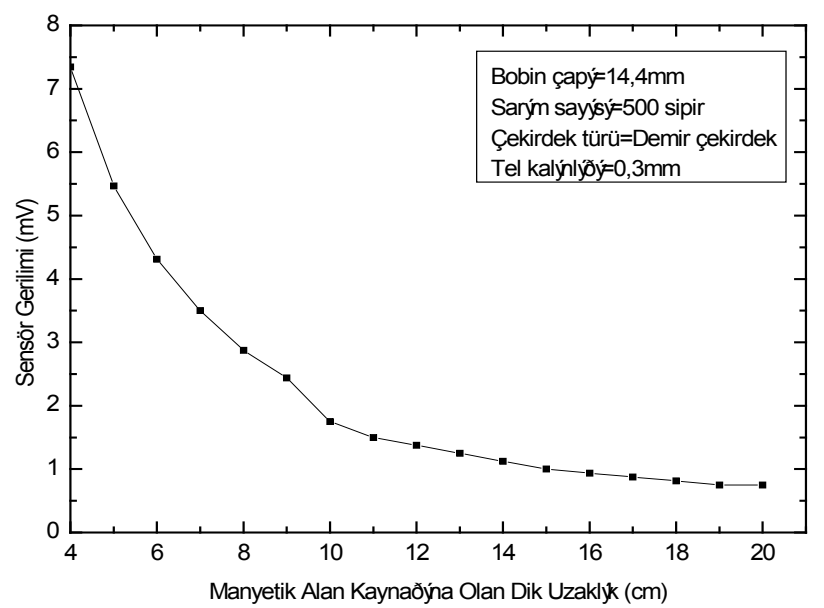

Şekil 7. Merkez doğrultusu boyunca bobin sensörde indüklenen gerilimin değişimi

\subsection{GMI Sensör İle Uzaktan Algılama}

Çalışmamızın ikinci aşamasında manyetik alan kaynağını değiştirmeden bu kez x-y tarayıcı sistem üzerine amorf telden oluşan GMI sensör yerleştirilerek uzaktan algılama çalışmaları yapılmıştır (Şekil 8).

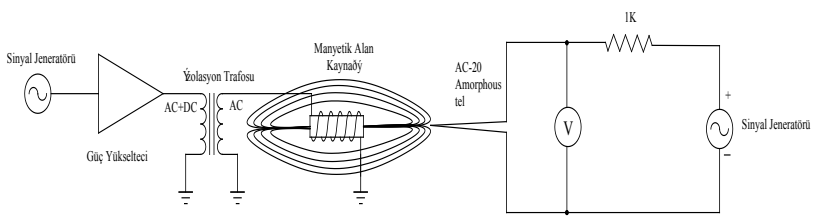

Şekil 8. GMI sensör ile uzaktan algılama
Amorf tel sensör bir manyetik alan içerisine bırakıldığında telin düzensiz yapıdaki manyetik momentleri mıknatıslanma yönünde dönmeye çalışmaktadır. Amorf tele uygulanan manyetik alanın yönüne bağlı olarak teldeki manyetik momentlerin yönelmeleri, telin hacmi değişmemek kaydiyla; telin boyunda uzamaya, kesitinde daralmaya veya telin boyunda kısalmaya, kesitinde büyümeye neden olacaktır. Bu durumda telin empedansında gerçekleşen GMI (Gaint Magneto Impedance) etki Denklem 10 ile verilir. Bu bağıntı aynı zamanda direnç ve kesit ile empedans arasındaki ilişkiyi de açıklamaktadır [6].

$$
Z=\left[\left(\frac{\mathrm{a} \cdot \mathrm{R}_{\mathrm{w}}}{2 \cdot \sqrt{2 \cdot \rho}}\right)^{2}+\left(\frac{1 \cdot \sqrt{2 \cdot \rho}}{2 \cdot \pi \cdot \mathrm{a}}\right)^{2}\right]^{\frac{1}{2}} \cdot \sqrt{\omega \cdot \mu_{0}}
$$

Bu bağıntıda;

$$
\begin{aligned}
& a: \text { Telin yarıçapı } \\
& \mathrm{R}_{\mathrm{w}}: \text { Telin doğru akımdaki elektriksel direnci } \\
& \rho: \text { Telin özgül direnci } \\
& 1: \text { Telin boyu } \\
& \omega: \text { Açısal frekans } \\
& \mu_{0}: \text { Ortamın manyetik geçirgenliği } \\
& \text { olarak tanımlanmaktadır. }
\end{aligned}
$$

Sensördeki empedans değişimi mıknatıslanma yönüyle ve şiddeti ile oldukça büyük değişimler gösterebilir. Mıknatıslanma vektörü, telden geçen akım ile paralel ise direnç en küçük değerini alırken, mıknatıslanma vektörü akıma dik ise direnç en büyük değerini alacaktır. Manyetik alan ile aynı yönde yönlenebilen manyetik momentlerin sayısı ne kadar çok olursa empedans değişimi dolayısıyla da gerilim değişimi o kadar çok olacaktır ki, bu özellikteki malzemeler alg1lama hassasiyeti açısından algılama sistemlerinde daha çok tercih edilmektedirler.

Çalışmamızda amorf tel bir AC kaynak ile direnç üzerinden beslenmektedir. Burada direnç amorf telden geçen akımı sınırlamaktadır. Besleme gerilimini ve frekansını ise amorf telin fiziksel özellikleri belirlemektedir. Yapılan testler, amorf telin $5 \mathrm{MHz}$ 'lik bir frekans ile beslendiğinde manyetik momentlerinin büyük çoğunluğunun uygulanan manyetik alan ile aynı yönde yönlenmeye çalıştığını dolayısıyla da maksimum empedans değişimine sebep olduğunu göstermiştir. Amorf telin besleme geriliminin değiştirilmesinin ise herhangi bir fiziksel (yapısal) değişikliğe neden olmadığı sadece amorf tel üzerine düşen gerilim değerinin besleme gerilimi ile orantılı olarak büyüdüğünü göstermiştir. 
Amorf telden akan 5 MHz'lik AC akım teldeki manyetik momentleri kendisi ile aynı yöne çevirmiştir. Bu durumda telin empedansı en küçük değerindedir. Amorf tel Şekil 8'deki gibi kıvrılarak elde edilen küçük yüzey manyetik alan kaynağına yaklaştırılacak olursa, bu küçük yüzeyde akım ile aynı yönde yönlenmiş manyetik momentler manyetik alanın etkisi ile $90^{\circ}$ dönmeye zorlanacaklardır. Dolayısıyla manyetik alan şiddeti ile orantılı olarak iletkenin boyunda bir miktar kısalma, kesitinde ise büyüme meydana gelerek telin empedansı artacaktır. Telin o yüzeydeki empedansının manyetik alan şiddeti ile orantılı artışı amorf telin üzerinden geçen akımı azaltıp, üzerine düşen gerilimi arttıracaktır. Manyetik alan kaynağından uzaklaştıkça amorf teldeki manyetik momentler tekrar akım ile aynı yönde yönlenecek ve uzayan tel boyu ile küçülen kesit tel empedansının tekrar en küçük değerini almasına, dolayısıyla da tel üzerine düşen gerilimin azalmasına neden olacaktır. Bu etki farklı besleme gerilimleri için Şekil 9'da görülmektedir.

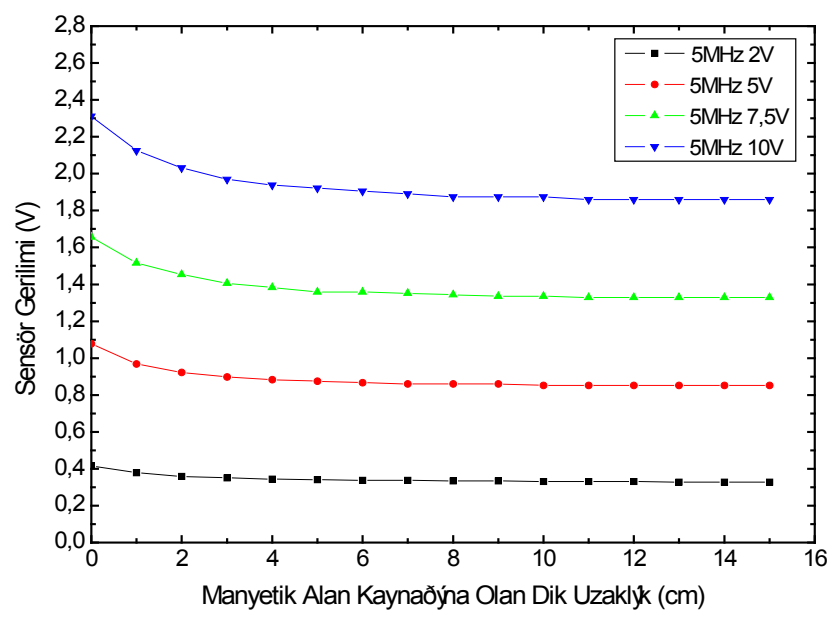

Şekil 9. GMI etki gösteren amorf tel sensörün manyetik alan kaynağından dik olarak uzaklaştırılmasıyla elde edilen eğriler

Şekil 9 incelendiğinde hiç yükseltme yapmaksızın $5 \mathrm{MHz}$ 'lik sabit bir frekansta değişik besleme gerilimlerinde amorf tel sensör ile yapılan ölçümlerde $12 \mathrm{~cm}$ 'den sonra sensör geriliminde herhangi bir değişim olmadığı gözlenmektedir. Bu uzaklık herhangi bir işleme maruz bırakılmamış amorf telin maksimum algılama yeteneğidir. Burada yükseltme yapabilmek için telin besleme frekansında sabit kazanç değeri ile yükseltme yapabilecek bir yükselteç tercih etmek gerekmektedir. Mevcut yükselteçler $5 \mathrm{MHz}$ 'lik bir frekansta oldukça küçük kazançlar ile yükseltme yapabilmektedir. Bu nedenle, daha uzak mesafelerden algılayabilmek için telin fiziksel özellikleri değiştirilerek manyetik alan değişimi ile telin empedansının değişiminin daha büyük olması sağlanmalıdır.

Deneysel çalışmamızda bobin sensör ve farklı besleme gerilimlerine sahip Amorf tel sensör verileri Şekil 10'da karşlaştırılmıştır.

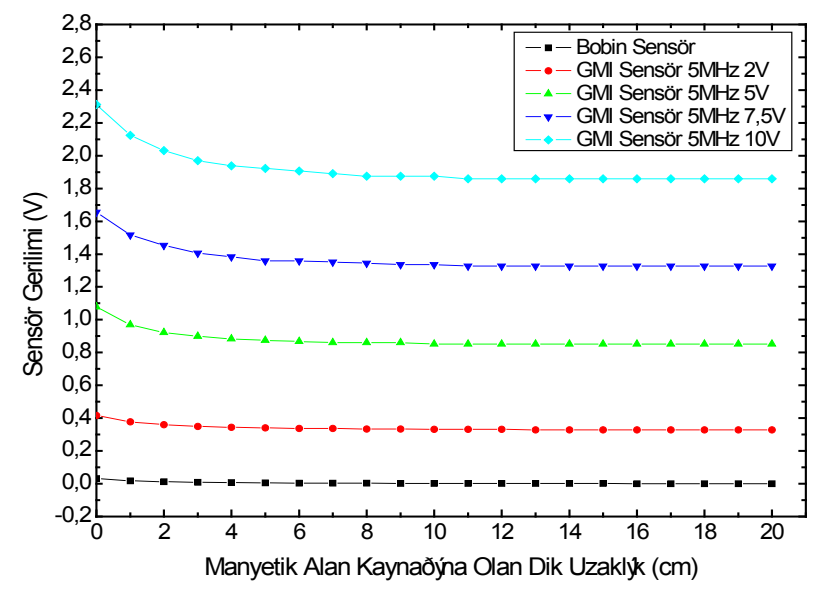

Şekil 10. Bobin sensör ile Amorf tel sensörün karşılaştırılması

\section{SONUÇLAR VE TARTIŞMA}

Şekil 10'dan da görüleceği gibi amorf tel sensörün aynı değerdeki manyetik alan içinde bobin sensöre göre daha geniş aralıkta gerilim değişimi gösterdiği görülmüştür. Buna rağmen bobin sensörün algıma mesafesinin amorf tel sensöre göre daha iyi olduğu belirlenmiştir. Bu mesafeler bobin için $18 \mathrm{~cm}$ (Şekil 7), $10 \mathrm{~V}$ besleme geriliminde amorf tel sensör için ise $12 \mathrm{~cm}$ (Şekil 9)'dir.

Literatürde demir çekirdekli bobin ile amorf tel sensörlerle uzaktan algılama üzerine elde edilen sonuçlar Şekil 11 'de verilmiştir.

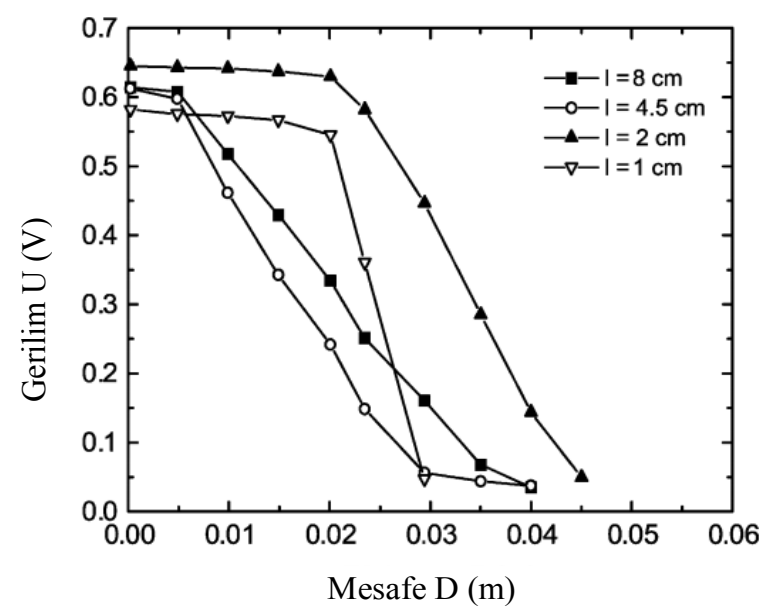

(a) 


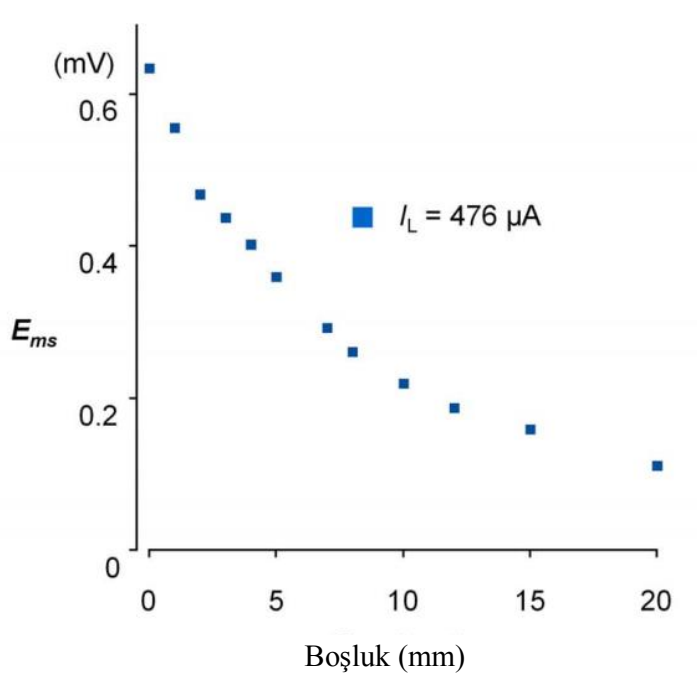

(b)

Şekil 11. a)Amorf tel sensör b) Demir çekirdekli bobin sensör ile elde edilen sonuçlar[10,11]

Şekil 11a'da görüldüğü gibi farklı manyetik alan kaynakları ve farklı manyetik geçirgenliğe sahip demir nüveler kullanılsa da, amorf tel sensör için elde edilen uzaktan algılama mesafeleri 4-5 cm aralığında olduğu görülmüsstür. $\mathrm{Bu}$ çalışmada manyetik alan kaynağ 1 , nüvenin manyetik geçirgenliği, sensörlerin besleme gerilimi, frekansı, uygun yükseltme kademesi ve amorf tel özellikleri bu algılama mesafesinin $12 \mathrm{~cm}$ 'ye çıkmasına olanak sağlamıştır. Ayrıca amorf telin 1sıl işleme tutulması da algılama mesafesini değiştirebilir. Çalışmanın ileri aşamaları bu yönde devam etmektedir.

Şekil 11b'ye bakıldığında bobin sensörlerle ulaşılan algılama mesafesinin çalışmamız sonuçlarıyla uyum içinde olduğu görülecektir. Fakat çok sarımlı bobin sensör yerine kesiti dikdörtgen yada kare olan helisel bobinler kullanılması direncin küçülmesi sebebiyle algılama mesafesini artabilir (Şekil 12).

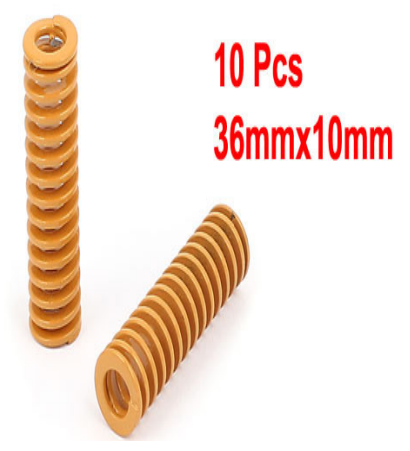

Şekil 12. Helisel bobin
Bölgesel okuma yapan bobin sensörlerde manyetik akı çizgilerinin düzgün olamadığı, yönün değişkenlik gösterdiği bölgelerde indüklenen gerilimler gürültü formunda olmakta ve çoğu zaman filtre devrelerinde kaybedilmektedir. Bu tür gerilim sinyalleri fourier analizi ile harmoniklerine ayrılmalı ve yüksek değişim gösteren harmonik izlenmelidir. Bu 50 $\mathrm{kHz}$ frekans uygulamaları için 2. harmoniğe denk gelmektedir[12].

\section{SONUÇ VE DEĞERLENDİRME}

Manyetik akı yoğunluğunun düşük olduğu bölgelerde bobin sensör gibi bölgesel okuma yapan sensörlerin, noktasal okuma yapan amorf tel sensörlere göre daha anlamlı sonuçlar verdiği bu çalışmada görülmüştür. Ayrıca bu çalışmada amorf tel sensörlerin, uzaktan algılama ve homojen olmayan manyetik alanların tespiti için uygun olmadığı belirlenmiştir. Bununla birlikte ortamdaki elektromanyetik gürültünün bobin sensörü daha fazla etkilediği de belirlenmiştir.

Amorf tel sensörler nokta okuma yaptıklarından daha çok yakın mesafede manyetik alan tespitinde tercih edilmelidir. Maliyet ve ulaşılabilirlik açısından bobin sensörler tercih edilse de hassasiyet açısından amorf tel sensörler seçilmelidir. Amorf tel sensörlerin doyum magnetizasyon değerlerini aşmayan hassas manyetik alan ölçümleri için tercih edilmesi uygun olacaktır.

Tahribatsız test metotlarında ise, (örneğin MFL) herhangi bir süreksizliğin; genişliği, derinliği ya da geometrisi gibi fiziksel nicelikleri tayin etme de noktasal okuma yapan manyetik sensörler tercih edilmektedir. Ayrıca sensör verilerinin bilgisayar ortamına alınırken yükseltme işlemi yapmaya gerek kalmadan yapılabilmesi elektromanyetik gürültülerin etkilerini azaltacaktır.

\section{KAYNAKLAR}

[1] Philips Semiconductors 1998 Jun 12 www.semiconductor. philips.com ,June 2007

[2] Kang, M.H., Choi, B.W., Koh, K.C., Lee, J.H., \& Park, G.T. (2005). Experimental study of a vehicle detector with an AMR sensor. Sensors and Actuators A-Physical, 118, 278284.

[3] Caruso, M.J., Bratland, T., Smith, C.H., \& Schneider, R. (2007, June). "A New perspective on magnetic field sensing "www.ssec.honeywell.com

[4] Lenz,J.E., (1990, June) A Review of magnetic sensors, IEEE Vol 78, No 6.

[5] Baldoni, J.A., \& Yellen, B.B. (2007). Magnetic tracking system: monitoring heart valve prostheses. Transactions on Magnetics, 43, 2430-2432. 
[6] Mahri,K., Panina,L.V., Uchiyama,T., Bushida,K., \& Noda,M. (1995, March). Sensitive and quick response micro magnetic sensor utilizing magneto-impedance in Co-rich amorphous wires IEEE Transactions on Magnetics. Vol.31.No.2.

[7] Göpel,W., Hesse,J., \& Zemel,J.N. ( 1989). Magnetic Sensors, Volume 5, New York.

[8] Göktepe,M., Ege,Y., Bayri,N., \& Atalay,S. (2007). Ferromanyetik malzemelerdeki çatlakların AC20 amorf tellerin algılayıcı olarak kullanılması ile bulunması. Afyon Kocatepe Üniversitesi Fen Bilimleri Dergisi. 7,(1),131-144.

[9] Das, T.K., Mitra, A., Mandal, S.K., Roy, R.K., Banerji, A. K., \& Panda, A.K. (2014, October). Parametric controls on giant magnetoimpedance (GMI) behaviour of $\mathrm{CoFeSiBCr}$ amorphous wires for prospective sensor applications. Sensors And Actuators, Elsevier, 382-387.

[10] Chiriac, C., \& Chiriac, H. (2003). Magnetic field and displacement sensor based on linear transformer with amorphous wire core. Sensors And Actuators, Elsevier, 172-173.

[11] Nakayama, S., \& Uchiyama, T. (2015, March). Real-time measurement of biomagnetic vector fields in functional syncytium using amorphous metal", Scientific Reports, 1-9. www. nature.com/scientificreports,(04/04/2018)

[12] Ege, Y., Çoramık, M., Kabadayı, M., Çıtak, H., Kalender, O., Yürüklü, E., ve ark. (2016). Anomaly detection with low magnetic flux: a fluxgate sensor network application. Measurement, 81, 43-56. 